Recebido em 11/2019. Aceito para publicação em 12/2019.

\title{
INFLUÊNCIA DE CATALISADORES DE CRAQUEAMENTO CATALÍTICO EM LEITO FLUIDIZADO (FCC) NAS PROPRIEDADES TÉRMICAS DE RESÍDUOS SÓLIDOS DE POLI(TEREFTALATO DE ETILENO)
}

\author{
INFLUENCE OF THE CATALYSTS OF CATALYTIC FLUIDIZED-BED CATALYTIC \\ CRACKING (FCC) ON THE THERMAL PROPERTIES OF SOLID POLY(ETHYLENE \\ TEREPHTHALATE) WASTE
}

\author{
Fábio Cesar Janotti ${ }^{1}$ \\ Florêncio Gomes de Ramos Filho
}

\begin{abstract}
Resumo: Devido à versatilidade e facilidade de acesso à matéria-prima, a utilização de materiais plásticos vem crescendo aceleradamente nos últimos anos em nossa sociedade. O poli(tereftalato de etileno) (PET), em especial, utilizado principalmente em embalagens, representa elevado percentual dos materiais plásticos descartados após o uso e, por isso, novos métodos de reciclagem vêm sendo desenvolvidos ao longo dos últimos tempos. Dando início a estudos que possam, no futuro, levar à viabilização do coprocessamento de resíduo sólido de PET em conjunto com as cargas convencionais dos processos tradicionais de FCC para a obtenção de hidrocarbonetos líquidos e gasosos, dando assim uma destinação mais nobre ao PET pós-consumo, avaliou-se, através de termogravimetria (TG) e calorimetria exploratória diferencial (DSC), a influência de dois tipos de catalisadores industriais de FCC (CAT1 e CAT2) à base de zeolitas, que por questões de segredo industrial não será revelada a sua composição, nas propriedades térmicas do PET pós-consumo, já que o processo industrial de FCC trata-se de um processo térmicocatalítico. Observou-se que o catalisador CAT1 apresentou melhores resultados para o aspecto de formação de menor quantidade de resíduo após a decomposição térmica do polímero, levando a uma maior conversão deste em outros produtos, e o catalisador CAT2 apresentou melhores resultados no aspecto da diminuição da entalpia de fusão do polímero.
\end{abstract}

Palavras-chave: Resíduos; PET; FCC; termogravimetria; DSC.

Abstract: Because of the versatility and ease of access to the raw material, the use of plastic materials has been growing rapidly in recent years in our society. Poly (ethylene terephthalate) (PET), in particular, mainly used in packaging, represents a high percentage of plastics discarded after use and, therefore, new recycling methods have been developed over the recent years. Initiating studies which may in the future lead to enabling the co-processing of PET solid residue together with the loads of conventional FCC traditional processes for obtaining oil and gas, leading to a more noble allocation of PET post-consumption, the influence of two types of FCC industrial catalysts (CAT1 and CAT2), whose composition will not be revealed for reasons of industrial secrecy, on the thermal properties of the PET post-consumption, was evaluated by thermogravimetric (TG) analysis and differential scanning calorimetry (DSC), since the industrial FCC process is a thermal-catalytic process. It was observed that the catalyst CAT1 presented the best results for the aspect of formation of the least amount of residue after the thermal decomposition of the polymer, leading to a higher conversion of it into other products, and the catalyst CAT2 showed the best results regarding the decrease in the melting enthalpy of the polymer.

Keywords: Waste; PET; FCC; thermogravimetry; DSC.

\footnotetext{
${ }^{1}$ Mestre, Fundação Centro Universitário da Zona Oeste - UEZO, Brasil. E-mail: fabiojanotti@gmail.com.

2 Doutor, Fundação Centro Universitário da Zona Oeste - UEZO, Brasil. E-mail: florênciogr@yahoo.com.
} 


\section{INTRODUÇÃO}

A civilização humana utiliza-se dos polímeros desde períodos bastante longínquos. Acredita-se que o uso da borracha natural para confeccionar diversos objetos data de 1600 anos antes de Cristo (HOSLER; BURKETT; TARKANIAN, 1999). Desde então o homem intensivou a utilização de plásticos e borrachas, primeiramente com polímeros naturais, resinas, borrachas naturais e cera, e, em uma época mais recente, a partir do século dezenove, a utilização de termoplásticos modernos.

A borracha vulcanizada foi desenvolvida por Charles Goodyear em 1839 e, nesta mesma época, o poliestireno foi descoberto por um boticário alemão. Tiveram sequencia, então, no século dezenove, diversos estudos com polímeros naturais e sintéticos, quando se desenvolveu materiais como o PVC (poli- cloreto de vinila) e a viscose. Já na primeira metade do século vinte, desencadeou-se uma série de descobertas na área, tendo sido este o período mais efusivo de desenvolvimento dos plásticos modernos, com a sintetização de pelo menos quinze novos polímeros (ANDRADY; NEAL, 2009).

O desenvolvimento da indústria dos plásticos é constante e, com o emprego de novas tecnologias que surgem para suprir as cada vez maiores demandas e necessidades, não surpreende a marca de 265 milhões de toneladas alcançadas pela produção mundial de plástico no ano de 2010.

Diversos fatores contribuem para o crescimento acelerado da utilização cada vez maior de artefatos produzidos a partir de materiais plásticos. Podemos citar sua matériaprima, oriunda do petróleo, produto explorado em larga escala em todo o mundo, o que faz com que não seja uma matéria-prima de difícil acesso. São materiais de baixo custo, com boa durabilidade e possibilidade de uso em diversas aplicações. Isto tudo influencia no aumento da quantidade de produtos desenvolvidos em materiais plásticos, o que vem trazendo benefícios para a sociedade em diversos aspectos (CANEVAROLO Jr, 2010).

Esta benéfica utilização dos materiais plásticos pela sociedade traz consigo um sério desafio: como dar a correta destinação a seus resíduos, que são prejudiciais ao meio-ambiente, incluindo aí os seres-humanos. Pode-se citar, dentre vários outros problemas, a grande quantidade de descarte pós-consumo, o elevado volume dos materiais plásticos e a disposição incorreta dos resíduos, que não são biodegradáveis e causam graves impactos ambientais. Além disso, devido ao uso de aditivos químicos durante o processo de fabricação, podem ocasionar danos à saúde dos seres humanos e de outros animais. Ações regulamentadoras com o objetivo de reduzir esses possíveis efeitos nocivos dos plásticos na saúde humana e no meio-ambiente precisam abarcar todo o seu ciclo, desde a produção, o uso, até o descarte.

No Brasil, entrou em vigor em 2010, instruída pela Lei 12.305, que trata, dentre outros, dos resíduos plásticos, a Política Nacional de Resíduos Sólidos. Esta lei 
estabeleceu estratégias para o desenvolvimento sustentável e impôs o sistema de logística reversa, além de tratar do ciclo de vida dos produtos e incentivar o reuso e a reciclagem de materiais e desincentivar o uso de aterros em favor de outras destinações mais favoráveis ao meio ambiente e à economia de recursos, seguindo a linha de ação de países desenvolvidos, como EUAe países da União Europeia, que empregam formas de tratamento de seus resíduos com impactos cada vez menores (OLIVEIRA, 2012).

O desenvolvimento de rotas alternativas para o reaproveitamento de resíduos plásticos é um tema de permanente discussão pelos governos, a fim de buscar aprimorar seus programas de gerenciamento de resíduos.

Diversos estudos mostram que, depois do reuso, a reciclagem é a forma menos impactante ao ambiente de reaproveitamento dos plásticos. Dentre os vários tipos de reciclagem, a mais utilizada no mundo é a mecânica.

Nas últimas décadas, os plásticos revolucionaram as nossas vidas. As possíveis aplicações (dos 12 plásticos) são praticamente inexauríveis. O que de fato é uma realidade na atualidade, já que podemos encontrar materiais plásticos nos mais diversos setores da sociedade, desde simples utensílios domésticos e vestuário, até peças de automóveis ou aviões, artefatos de engenharia e até em aplicações médicas e odontológicas (THOMPSON et al., 2009). A versatilidade dos polímeros facilita a produção desta diversidade de produtos que proporcionam economia de energia, avanços tecnológicos e diversos outros benefícios para a sociedade (ANDRADY; NEAL, 2009).

A maior parte dos artigos plásticos comercializados, destacando-se as embalagens e outros bens-não duráveis, torna-se resíduo em períodos menores que um ano e, no pior cenário, após um único uso. Contudo, os resíduos plásticos podem ser considerados valiosas fontes de matérias-primas e podem ser convertidos em energia ou em outros materiais poliméricos (AL-SALEM; LETTIERI; BAEYENS, 2010).

A escassez de espaço e os custos cada vez maiores para a implantação de novos aterros têm impulsionado o desenvolvimento de técnicas alternativas para a disposição de resíduos plásticos. Como o problema dos impactos ambientais dos plásticos agravase quando estes são dispostos de forma inadequada e dispersos no ambiente, técnicas de reciclagem e incineração vêm sendo cada vez mais praticadas (OLIVEIRA, 2012).

Dentro deste viés, novos métodos de reciclagem vêm sendo desenvolvidos ao longo dos últimos tempos e é neste campo que este trabalho pretende atuar, dando início a estudos que possam, no futuro, levar à viabilização do co-processamento de resíduo sólido de PET em conjunto com as cargas convencionais dos processos tradicionais de Craqueamento Catalítico em Leito Fluidizado (FCC) para a obtenção de hidrocarbonetos líquidos e gasosos, dando assim uma destinação mais nobre ao PET pós-consumo.

Assim, nesse trabalho avaliou-se a influência de catalisadores de FCC nas 
propriedades térmicas de resíduos sólidos de PET pós-consumo visando futura aplicação do polímero como carga para coprocessamento em unidades de craqueamento catalítico de FCC juntamente com cargas originadas na destilação do petróleo, bem como investigar o grau de influência destes catalisadores nos processos térmicos envolvendo o polímero em estudo, já que o processo industrial de FCC tratase de um processo térmico-catalítico.

Como objetivos específicos, buscou-se: $i$ ) verificar o comportamento das curvas TG-DTG e DSC do PET na presença de zeólitas nos principais processos de FCC existentes com relação aos polímeros puros; ii) determinar o catalisador, bem como sua concentração, que mais demonstra diminuição de formação de resíduo final no processo de decomposição térmica do PET e iii) determinar o catalisador, bem como sua concentração, que mais demonstra otimização enérgica no processo de decomposição térmica do PET.

\section{MATERIAIS E MÉTODOS}

\subsection{Preparo das Amostras}

Utilizou-se, no preparo das amostras, pó de Poli(tereftalato de etileno) PET pósconsumo fornecido pela empresa CPR Rio, empresa especializada na fabricação de resina PET PCR, ou seja, pós-consumo reciclada, e de preformas PET, localizada em Xerém-RJ.

Os catalisadores empregados foram cedidos pelo Centro de Pesquisas da Petrobrás e são oriundos de duas refinarias diferentes: uma de processamento convencional (FCC), que será chamado de CAT1, e o outro de processamento de resíduos atmosférico e de vácuo (RFCC), que será chamado de CAT2. Os catalisadores são a base de zeólitas. Os detalhes da composição dos catalisadores não serão divulgados devido a exigência de sigilo industrial da empresa fornecedora.

Estes catalisadores são descarregados das unidades industriais com a atividade padrão desejada para os processos de craqueamento catalítico nas refinarias.

Com o auxílio de uma balança com precisão de $0,1 \mathrm{mg}$, procedeu-se a pesagem dos materiais para que se alcançassem as relações PET/catalisador, em massa, que são mostradas na Tabela 1. 
Tabela 1 - Composição das amostras analisadas

\begin{tabular}{cccc}
\hline Amostra & CAT1 (\%) & CAT2 (\%) & PET (\%) \\
\hline A1 & 0,0 & 0,0 & 100,0 \\
A2 & 5,0 & 0,0 & 95,0 \\
A3 & 10,0 & 0,0 & 90,0 \\
A4 & 15,0 & 0,0 & 85,0 \\
A5 & 25,0 & 0,0 & 75,0 \\
A6 & 0,0 & 0,0 & 100,0 \\
A7 & 0,0 & 5,0 & 95,0 \\
A8 & 0,0 & 10,0 & 90,0 \\
A9 & 0,0 & 15,0 & 85,0 \\
A10 & 0,0 & 25,0 & 75,0 \\
\hline
\end{tabular}

Fonte: Os autores.

Os materiais foram devidamente pesados em vidros de relógio e transferidos nas massas desejadas para recipientes de vidro com capacidade de $500 \mathrm{~mL}$ e dotados de fechamento hermético para que pudesse ser realizada a homogeneização do material, que ocorreu por agitação manual com duração de aproximadamente 15 minutos para cada amostra. Após a homogeneização, as amostras foram transferidas para recipientes plásticos menores com tampas lacradas e encaminhadas para a realização das análises laboratoriais.

\subsection{Análises Térmicas}

\subsubsection{Termogravimetria (TG)}

Foi utilizado o equipamento, SDT Q600, da TGA Instruments, com taxa de aquecimento de $10^{\circ} \mathrm{C} / \mathrm{min}$, temperatura máxima de $600^{\circ} \mathrm{C}$ e atmosfera de $\mathrm{N}_{2}$.

\subsubsection{Calorimetria exploratória diferencial (DSC)}

Foi utilizado o equipamento DSC200 F3, da Netzsch, com razão de aquecimento de $10^{\circ} \mathrm{C} / \mathrm{min}$, atmosfera inerte de $\mathrm{N}_{2}$, faixa de temperatura de 30 a $350^{\circ} \mathrm{C}$ e amostras com aproximadamente $0,5 \mathrm{mg}$. 


\section{RESULTADOS E DISCUSSÃO}

\subsection{Termogravimetria}

A Figura 1 apresenta a curva termogravimétrica para a amostra 1, composta apenas por pó de PET pós-consumo, sem adição de catalisadores, sendo, portanto, o parâmetro de comparação para os demais resultados, no que diz respeito à variação das temperaturas de início de degradação e temperatura máxima de degradação e, principalmente, da variação da quantidade de resíduo final gerada, já que quanto menor tiver sido o percentual de resíduo final, maior terá sido a conversão do polímero em outros produtos (RIBEIRO, 2009). As curvas das demais amostras apresentaram perfis semelhantes, com alteração nas temperaturas $T_{\text {onset }}, T_{\text {endset, }} T_{\text {pico }}$ e massa residual, como será visto mais à frente.

Figura 1 - Curva termogravimétrica da amostra A1 (PET puro).

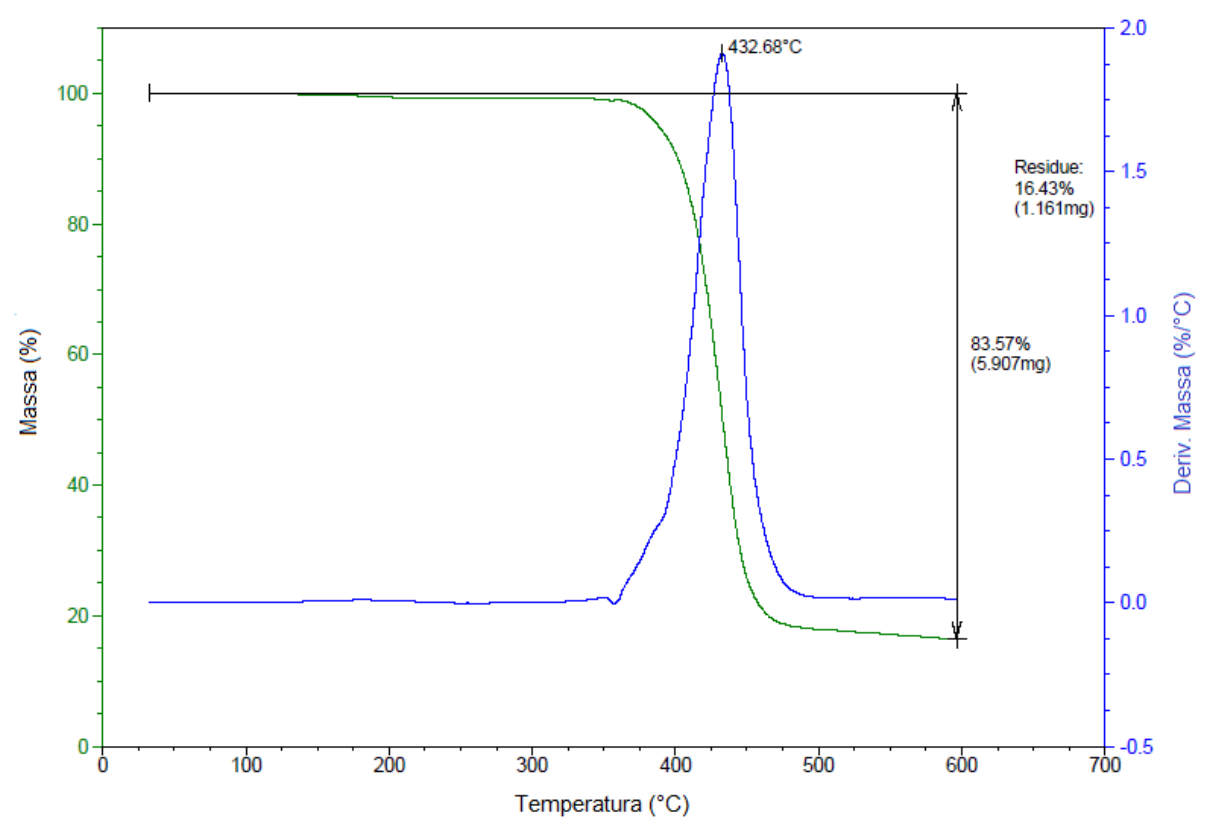

Fonte: Os autores.

Analisando a curva do PET puro (Fig. 1), pode-se verificar que o resíduo final apresentado foi de $16,4 \%$, com uma temperatura de início de degradação ( $T_{\text {onset }}$ ) de aproximadamente $363,2^{\circ} \mathrm{C}$, tendo atingido uma temperatura máxima $\left(T_{\text {pico }}\right)$ de $432,68^{\circ} \mathrm{C}$ e temperatura final de degradação ( $\left.T_{\text {endset }}\right)$ de aproximadamente $493,22^{\circ} \mathrm{C}$.

É importante ressaltar que para as amostras que sofreram adição de catalisador, para que tenhamos o valor real da massa residual final (medido a $600^{\circ} \mathrm{C}$ ) apresentado, se faz necessário subtrair da massa da amostra o valor equivalente à proporção de 
catalisador adicionada, já que, nas condições da análise, os componentes do catalisador se mantém inertes, restando apenas o resíduo referente ao polímero (PET). Esse valor será tomado como Resíduo Real. Os valores corrigidos são mostrados na Tabela 2.

Tabela 2 - Valores da massa residual (medida a $600^{\circ} \mathrm{C}$ ) corrigido (Resíduo real) das amostras.

\begin{tabular}{ccccccc}
\hline Amostra & $\begin{array}{c}\text { CAT1 } \\
(\%)\end{array}$ & $\begin{array}{c}\text { CAT2 } \\
(\%)\end{array}$ & $\begin{array}{c}\text { Massa de } \\
\text { catalisador } \\
(\mathbf{m g})\end{array}$ & $\begin{array}{c}\text { Resíduo } \\
\text { lido }(\mathbf{m g})\end{array}$ & $\begin{array}{c}\text { Resíduo } \\
\text { real (mg) }\end{array}$ & $\begin{array}{c}\text { Resíduo } \\
\text { real (\%) }\end{array}$ \\
\hline A1 & 0 & 0 & 0 & 1,161 & 1,1610 & 16,4 \\
A2 & 5 & 0 & 0,3157 & 0,9526 & 0,6369 & 10,6 \\
A3 & 10 & 0 & 0,6211 & 0,9526 & 0,3315 & 5,9 \\
A4 & 15 & 0 & 0,9372 & 1,663 & 0,7258 & 13,7 \\
A5 & 25 & 0 & 1,8135 & 2,468 & 0,6545 & 12,0 \\
A6 & 0 & 0 & 0 & 1,161 & 1,1610 & 16,4 \\
A7 & 0 & 5 & 0,32145 & 1,391 & 1,0696 & 17,5 \\
A8 & 0 & 10 & 0,6282 & 1,278 & 0,6498 & 11,5 \\
A9 & 0 & 15 & 1,01715 & 1,655 & 0,6379 & 11,1 \\
A10 & 0 & 25 & 1,85825 & 2,444 & 0,5858 & 10,5 \\
\hline
\end{tabular}

Fonte: Os autores.

A Figura 2 apresenta os valores de resíduo final já corrigidos (Tabela 2) na forma de dispersão, a fim de se observar o comportamento das amostras ao redor do valor encontrado para a amostra de referência (PET puro).

Pode-se observar que todas as amostras contendo catalisador, exceto a A7, apresentaram percentuais menores de resíduo final do que as amostras de referência (amostras A1 e A6).

As amostras contendo o catalisador de FCC (CAT1) apresentaram redução média de $35,7 \%$ na formação de resíduo em comparação com o resíduo gerado peça decomposição térmica do PET sem catalisador, enquanto que as amostras contendo catalisador de RFCC (CAT2) apresentaram redução média de 23,0\% na formação de resíduo final. Desta maneira, podemos afirmar que ambos os catalisadores atuam de maneira positiva no sentido de melhorar o rendimento da conversão do polímero, porém o CAT1 atua de maneira mais efetiva, tendo tido destaque a amostra A3, contendo $10,0 \%$ em massa do CAT1, que obteve redução de $63,9 \%$ na formação de resíduo final. 
Figura 2 - Valores do Resíduo Real das amostras.

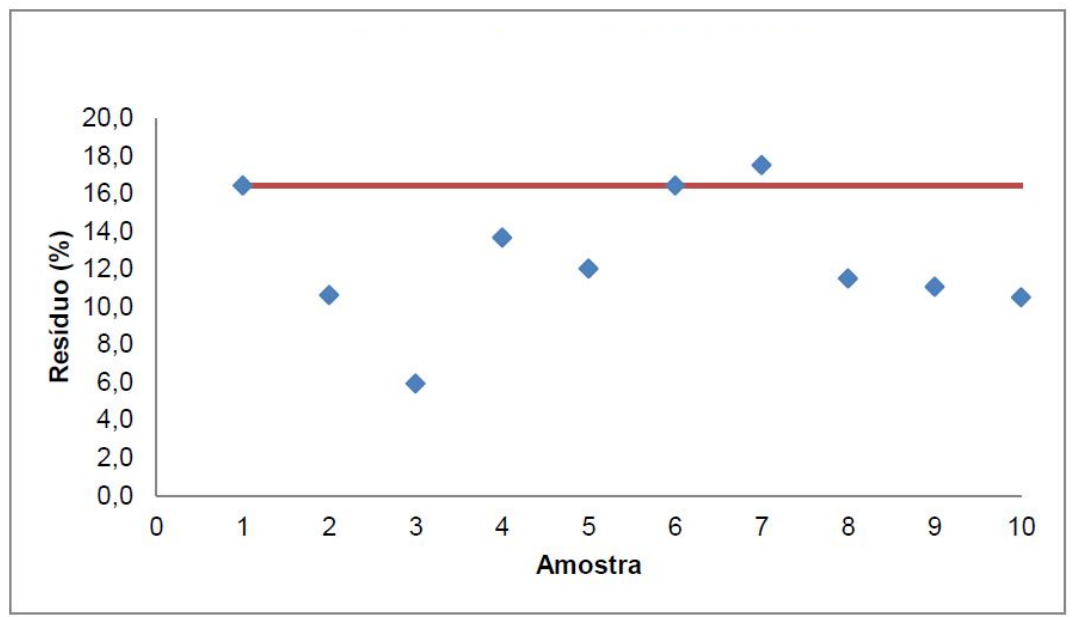

Fonte: Os autores.

A Tabela 3 apresenta os valores obtidos para temperatura inicial de degradação ( $T_{\text {onset }}$ ), temperatura final ( $\left.T_{\text {endset }}\right)$ e temperatura máxima ( $\left.T_{\text {pico }}\right)$ para todas as amostras analisadas.

Tabela 3 - Valores de $\mathrm{T}_{\text {onset, }} \mathrm{T}_{\text {endset }}$ e $\mathrm{T}_{\text {pico }}$ para todas as amostras

\begin{tabular}{cccccc}
\hline Amostra & CAT1 (\%) & CAT2 (\%) & $\mathbf{T}_{\text {pico }}\left({ }^{\circ} \mathbf{C}\right)$ & $\mathbf{T}_{\text {onset }}\left({ }^{\circ} \mathbf{C}\right)$ & $\mathbf{T}_{\text {endset }}\left({ }^{\circ} \mathbf{C}\right)$ \\
\hline A1 & 0 & 0 & 432,68 & 363,2 & 493,22 \\
A2 & 5 & 0 & 433,20 & 354,24 & 508,67 \\
A3 & 10 & 0 & 434,00 & 349,64 & 497,57 \\
A4 & 15 & 0 & 434,09 & 339,52 & 501,57 \\
A5 & 25 & 0 & 434,26 & 347,07 & 506,41 \\
A6 & 0 & 0 & 432,68 & 363,2 & 493,22 \\
A7 & 0 & 5 & 433,23 & 345,52 & 493,48 \\
A8 & 0 & 10 & 433,68 & 331,49 & 494,54 \\
A9 & 0 & 15 & 433,99 & 353,86 & 500,75 \\
A10 & 0 & 25 & 434,15 & 323,6 & 500,27 \\
\hline
\end{tabular}

Fonte: Os autores.

Na Figura 3 é apresentado o gráfico com os valores das temperaturas máximas de degradação ( $\left.T_{\text {pico}}\right)$ para cada amostra. Pode-se verificar que não houve variação significativa entre as amostras e o branco. Este comportamento era esperado, visto que a presença de catalisador não altera a estrutura do material polimérico, influenciando 
apenas na duração do evento térmico.

Os resultados obtidos por TG indicaram que todas as amostras que receberam adição de catalisador, seja o utilizado nas unidades de FCC ou o utilizado nas unidades de RFCC, apresentaram diminuição no percentual de resíduo final, o que representa que os catalisadores empregados atuam de maneira efetiva na rota de decomposição térmica do PET, aumentando o grau de conversão do polímero em outros produtos.

Figura 3 - Comparação dos valores de $T_{\text {pico }}$ das amostras

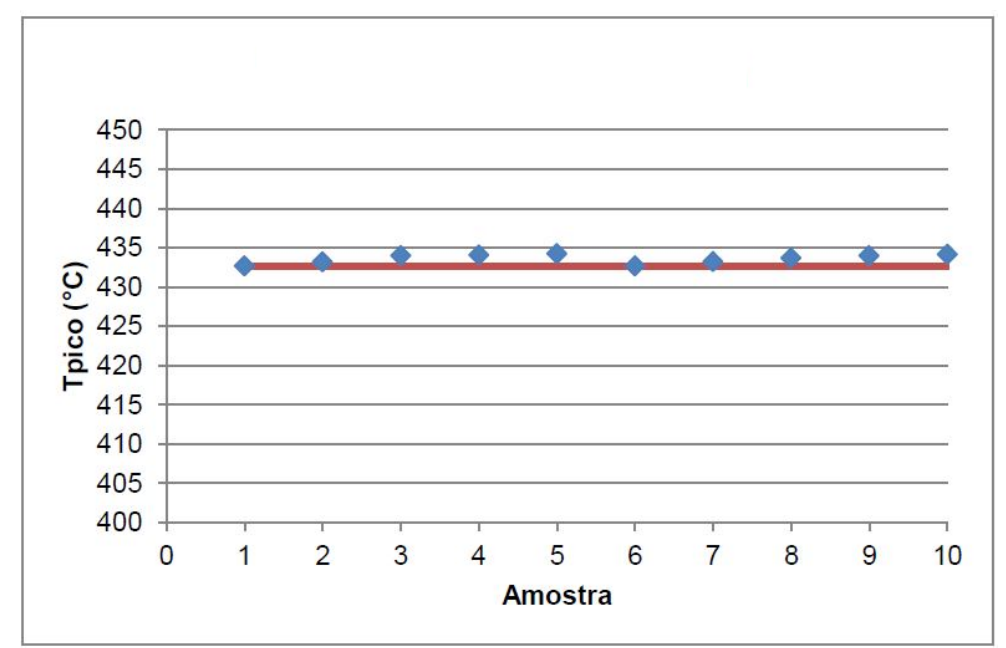

Fonte: Os autores.

Os valores de temperatura de início de degradação, Tonset, são apresentados na Figura 4 de cada amostra para fins de comparação.

Pode-se aferir que todas as amostras contendo catalisador apresentaram Tonset menores que a das amostras de referência, tendo destaque a amostra 10 que apresentou a maior variação em relação ao polímero puro.

Figura 4 - Comparação dos valores de Tonset das amostras estudadas.

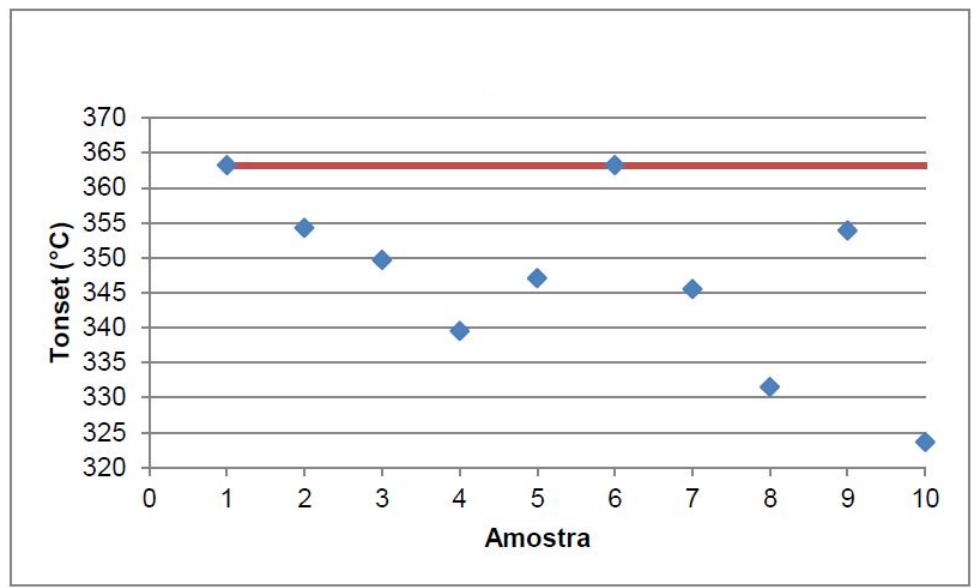

Fonte: Os autores. 
Por último, a Figura 5 apresenta o gráfico dos valores das temperaturas finais de degradação ( $\left.T_{\text {endset}}\right)$ para cada amostra.

Figura 5 - Representação comparativo dos valores de Tendset das amostras em estudo.

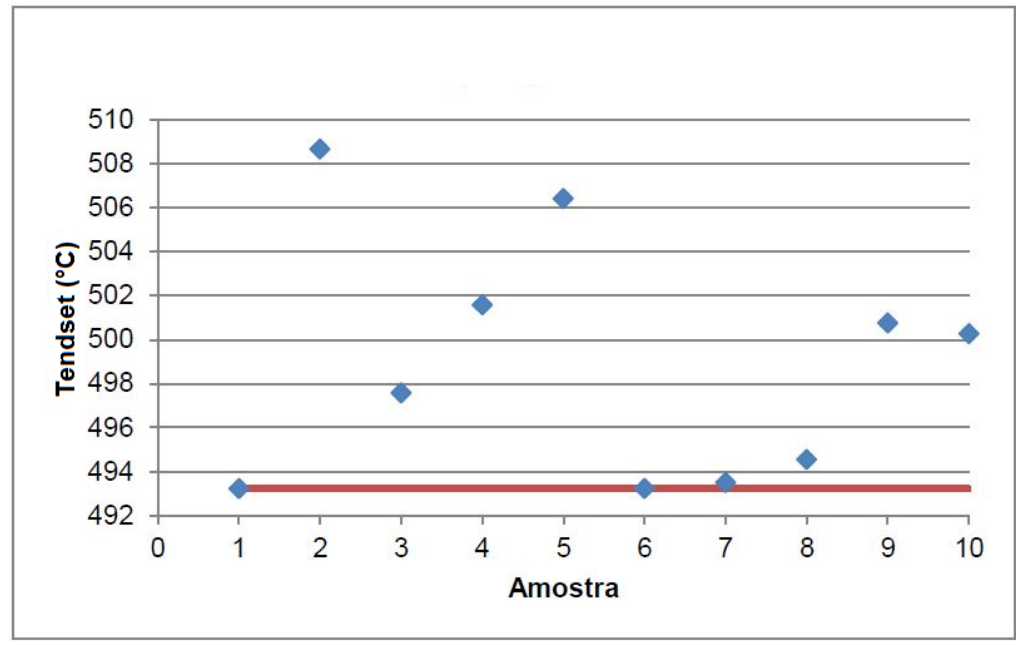

Fonte: Os autores.

Com exceção da amostra 7 , todas as amostras contendo catalisador apresentaram $T_{\text {endset }}$ superiores à da amostra de referência (PET puro).

Todas as amostras contendo catalisador apresentaram redução de $\mathrm{T}_{\text {onset }} \mathrm{e}$ elevação de $T_{\text {endset, }}$ aumentando a faixa de temperatura em que ocorre a decomposição do polímero, o que contribui para uma maior conversão e redução do percentual de resíduo formado, confirmando os resultados indicados anteriormente.

\subsection{Calorimetria exploratória diferencial (DSC)}

A Figura 6 apresenta a curva de DSC para o PET pós-consumo (amostra 1), sem adição de catalisadores, sendo, portanto, o parâmetro de comparação para os demais resultados, no que diz respeito à variação das temperaturas de fusão $\left(T_{m}\right)$ e, principalmente, da variação da entalpia de fusão $\left(\Delta \mathrm{H}_{\mathrm{m}}\right)$ das amostras, já que quanto menor tiver sido o calor de fusão, maior terá sido o ganho energético para a conversão do polímero em outros produtos. As curvas das demais amostras estão mostradas na Figura 7. 
Figura 6 - Curva de DSC para o PET pós-consumo, sem adição de catalisadores.

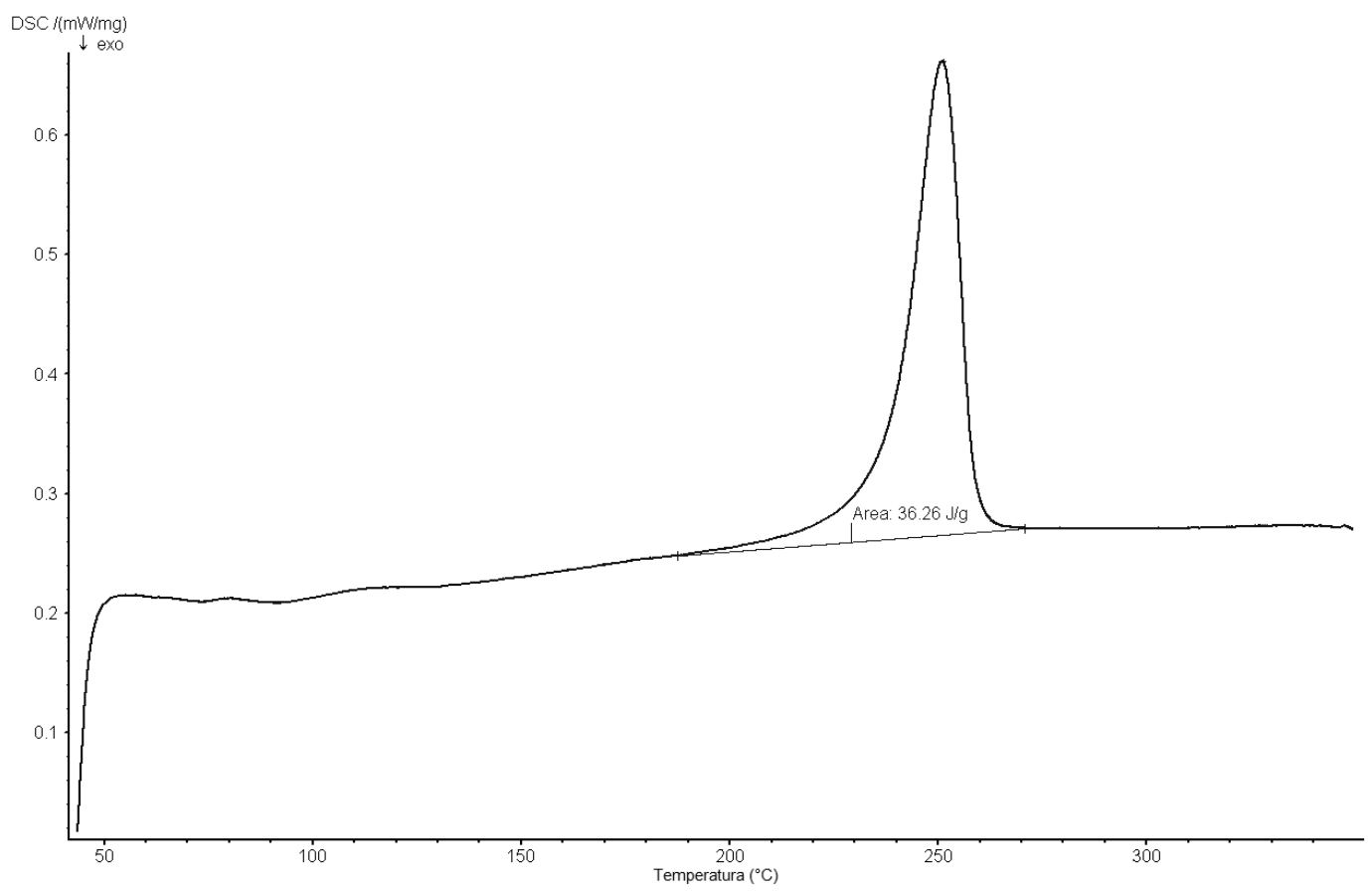

Fonte: Os autores.

As amostras 2, 3, 4 e 5, com respectivamente 5, 10, 15 e 25\% do CAT1, apresentaram temperatura de fusão $\left(T_{m}\right)$ de $251,2,251,3,251,1$ e $251,1^{\circ} \mathrm{C}$. Suas entalpias de fusão $\left(\Delta H_{m}\right)$ foram de $40,41,41,35,39,55$ e 35,82 J/g.

Para efeito de composição de tabelas e gráficos, repetiu-se os resultados da amostra A1 (branco para as amostras com CAT1) para a amostra A6 (branco para as amostras com CAT2).

As amostras 7, 8, 9 e 10, com respectivamente 5, 10, 15 e 25\% do CAT2, apresentaram temperatura de fusão $\left(T_{m}\right)$ de $251,7,251,1,251,3$ e $251,2^{\circ} \mathrm{C}$. Suas entalpias de fusão $\left(\Delta H_{m}\right)$ foram de $43,64,34,70,39,50$ e 30,65J/g. 
Figura 7 - Curvas de DSC para as amostras de PET com catalisadores (CAT1 e CAT2)

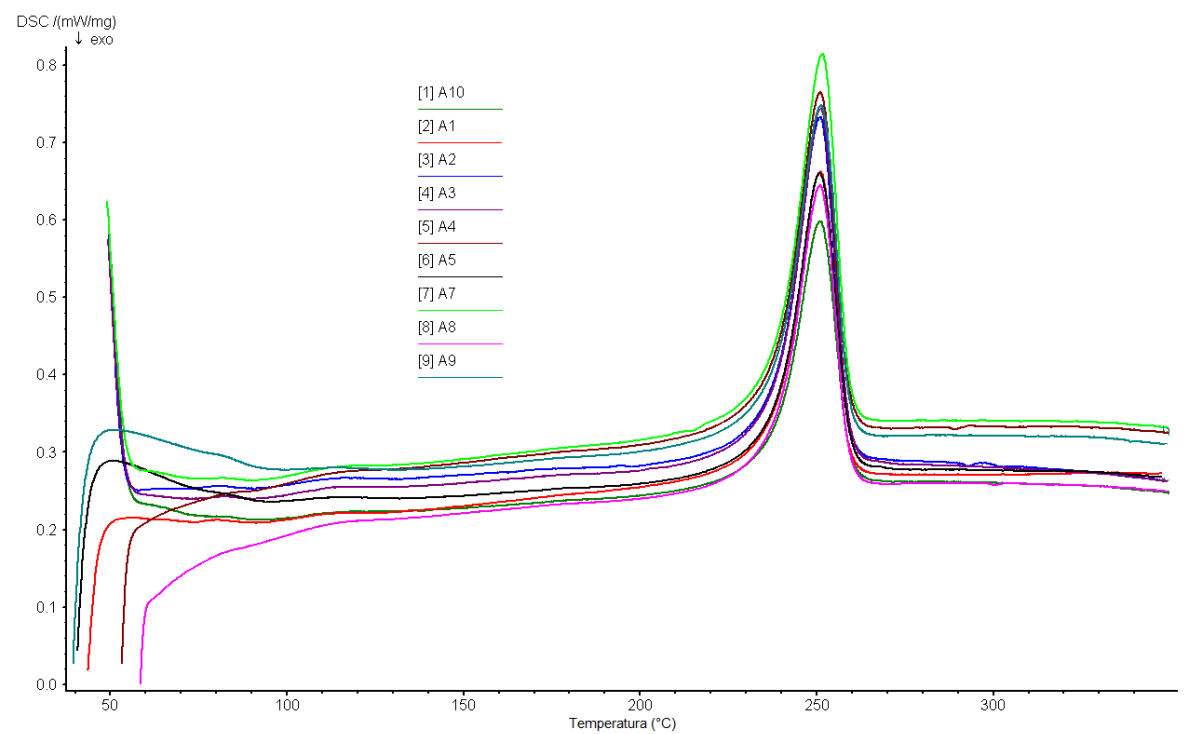

Fonte: Os autores.

Importante ressaltar que, neste estudo, apenas os resultados encontrados na curva do primeiro aquecimento são relevantes, já que para o processo proposto de utilização do PET como carga para unidades de FCC, a decomposição térmica do PET pós-consumo se dá de maneira total, não havendo a possibilidade de ocorrer resfriamento posterior.

Na Figura 8 são apresentadas as temperaturas de fusão encontradas para cada amostra. Pode-se observar que não houve variação significativa de $T_{m}$ para as amostras em estudo.

Figura 8 - Comparação dos valores de $T_{m}$ das amostras estudadas.

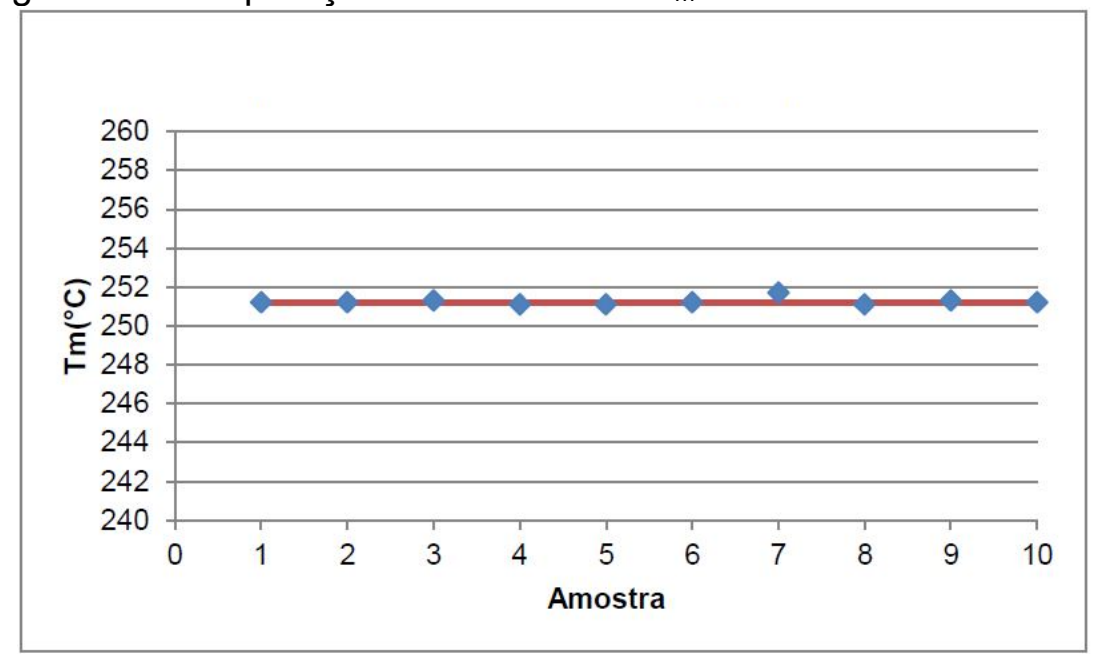

Fonte: Os autores. 
A Figura 9 mostra os valores de entalpia de fusão $\left(\Delta H_{m}\right)$, para cada amostra, comparando com o valor encontrado para as amostras de referência (PET puro pósconsumo). Pode-se aferir que as amostras A2, A3, A4, A7 e A9 apresentaram valores de $\Delta \mathrm{H}_{\mathrm{m}}$ superiores aos da amostra de PET pós-consumo, enquanto que as amostras $\mathrm{A} 5$, A8 e A10 apresentaram valores inferiores.

Figura 9 - Comparação dos valores de $\Delta \mathrm{H}_{\mathrm{m}}$ entre as amostras com a incorporação dos catalisadores e o PET puro pós-consumo.

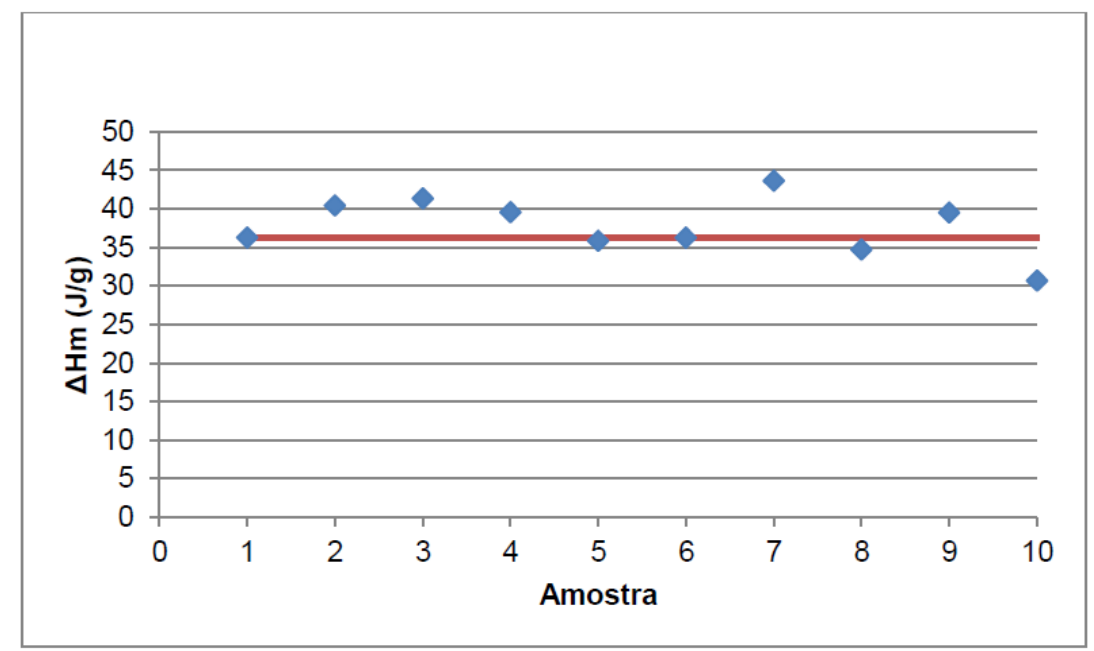

Fonte: Os autores.

Os resultados obtidos nas análises de DSC indicaram que o catalisador CAT1 não é eficaz para diminuir a entalpia de fusão do PET e que as amostras contendo o catalisador CAT2 apresentaram melhores resultados neste aspecto, tendo sido a amostra $\mathrm{A} 10$, contendo $25 \%$ de CAT2, a que apresentou menor $\Delta \mathrm{H}_{\mathrm{m}}(30,65 \mathrm{~J} / \mathrm{g}), 15,5 \%$ abaixo da entalpia de fusão obtida para o PET sem catalisador.

\section{CONCLUSÕES}

Pode-se concluir, portanto, que os catalisadores empregados em unidades industriais de Craqueamento Catalítico em Leito Fluidizado (FCC), tanto em unidades convencionais, quanto nas que se utilizam de resíduos atmosférico e de vácuo como matéria-prima, quando empregados em amostras de poli(tereftalato de etileno) pósconsumo, alteram suas propriedades térmicas de maneira positiva, sendo que o catalisador CAT1 apresentou melhores resultados para o aspecto de formação de menor quantidade de resíduo após a decomposição térmica do polímero, levando a uma maior conversão deste em outros produtos, e o catalisador CAT2 apresentou melhores resultados no aspecto da diminuição da entalpia de fusão do polímero. 


\section{REFERÊNCIAS}

AL-SALEM, S. M.; LETTIERI, P.; BAEYENS, J. The valorization of plastic solid waste (PSW) by primary to quaternary routes: From re-use to energy and chemicals, Progress in Energy and Combustion Science, v. 36, p. 103-129, fev. 2010.

ANDRADY, A. L.; NEAL, M. A. Applications and Societal Benefits of Plastics, Philosophical Transactions of the Royal Society B, v. 364, p. 1977-1984, 2009.

CANEVAROLO JR., S.V. Ciência dos Polímeros: um texto básico para tecnólogos e engenheiros. 3. ed. São Paulo: Artilber Editora, 2010.

HOSLER, D.; BURKETT, S.L.; TARKANIAN, M.J. Prehistoric Polymers: Rubber Processing in Ancient Mesoamerica. Science, v. 284, n. 18, p. 1988-1991, jun. 1999.

OLIVEIRA, M. C. B. R. Gestão de Resíduos Plásticos Pós-Consumo: perspectivas para a Reciclagem no Brasil. 2012. Dissertação (Mestrado em Planejamento Energético) - Universidade Federal do Rio de Janeiro, 2012.

RIBEIRO, M.P. Aplicação de termogravimetria acoplada à espectrometria de massas para a caracterização de petróleo e determinação da curva de evolução de gás sulfídrico. 2009. Tese (Doutorado em Ciência e Engenharia de Petróleo) Universidade Federal do Rio Grande do Norte, Moçoró, 2009.

THOMPSON, R. C. et al. Plastics, the environment and human health: current consensus and future trends. Philosophical Transactions B, v. 364, p. 2153-2166, 2009. 